\title{
100 years of history and prospects in thoracic surgery
}

\author{
Pedro Henrique Xavier Nabuco de Araujo ${ }^{1}$, José Ribas Milanez de Campos ${ }^{2}$, \\ Paulo Manuel Pêgo-Fernandes ${ }^{3}$
}

\section{History of Thoracic Surgery Worldwide}

$\mathrm{T}$ here is no exact date or specific event that marks the birth of thoracic surgery. Its appearance did not occur in any particular country or particular school. It seems that after the advent of anesthesia and the better understanding of sepsis, physicians in several countries began to explore possible applications of surgical techniques for relieving thoracic diseases. Many events and characters were involved in such origin, making it truly multinational ${ }^{1}$.

From the beginning, thoracic surgery has always been related to the treatment of tuberculosis. In 1882 , Forlanini, a medical professor in Pavia, introduced the concept of artificial pneumothorax in the treatment of cavities in tuberculosis. Although he was a clinical medicine and pathology professor, De Cérenville from Lausanne described costal resections for lung collapse em 1885. However, other pathologies were also treated with surgery at the end of the nineteenth century: Rehn de Frankfurt described in 1897 the success of suturing a wound caused by knife in the right ventricle of a young man and, im the same year, Beck from New York advocated for visceral pleurectomy for the radical treatment of empyema. Then, in the early twentieth century, Stockholm Jacobaeus introduced the thoracoscopic for closed intrapleural pneumolysis, performing the first minimally invasive surgeries in history ${ }^{2}$.

Just as the advent of anesthesia was fundamental for the progress of surgery, control of ventilation during surgery allowed for the expansion of modern thoracic surgery. In 1904, Johann von Mikulicz, from Brelau, Poland, began conducting research on differential pressure control, enabling the patiet to keep breathing during surgery. Sauerbruch, Johann von Mikulicz's apprentice, developed the negative differential pressure chamber, a complicated system in which the patient and the entire surgical team were enclosed in a hermetically closed room, leaving only the head of the patient out under atmospheric pressure, so that the anesthetics could be administered. Meanwhile, Brauer de Marburg, from Germany, was developing a prositive pressure method that surrounded only the patient's head with a kind of diving helmet for the application of anesthesia and positive pressure ventilation.

1. Assistant Professor of the FMUSP's Department of Cardiopneumology, Thoracic Surgeon at the HCFMUSP. Email: phnabuco@, icloud.com

2. Professor at FMUSP, Thoracic Surgeon at the HCFMUSP. Email: jribas@usp.br

3. Full Professor of the FMUSP's Thoracic Surgery Discipline, HCFMUSP's Head of the Thoracic Surgery Division. Email: paulopego@ incor.usp.br

Mailing address: Prof. Dr. Paulo Manuel Pêgo-Fernandes. Divisão de Cirurgia Torácica, InCor-HCFMUSP. Av. Dr. Enéas de Carvalho Aguiar, $n^{\circ} 44,2^{\circ}$ andar. (2nd floor) São Paulo, SP, Brasil. ZIP CODE: 05403-000. 
Robinson from Massachusetts General Hospital, in Boston, improved this positive pressure "helment" in 1910. All of this worked as a prelude to the work of Meltzer and Auer, from New York, in 1909 with "continuous breathing without respiratory motion" through endotracheal insufflation with a continuous stream of air and anesthetic vapor. This led, finally, to the application of intermittent positive pressure breathing through a cuffed endotracheal tube (the development of such tube was initiated in 1896 by Tuffier, Paris) Thus, the emergence of lung inflation by positive pressure was the cornerstone that enabled the future development of thoracic surgery ${ }^{3}$.

Since it became possible to ventilate the anesthetized patient with his/her chest open, the anatomical lung resection techniques have been improving. At first, lobectomy was performed with a mass ligature of the elements of the pulmonary hilum, and resection could be performed in two stages (in the first moment a mechanical and chemical pleurodesis was carried out, and in the second moment lobectomy was performed) as described in 1922 by Lilienthal from New York for the treatment of bronchiectasis. At this moment in time before the development of antibiotics, surgical mortality rates were high (about 43\%). Another publication, by Brunn, established a more modern lobectomy technique with individual ligation of hilar vessels, suture of the bronchial stump (and covering it with adjacent lung tissue) and closing of the chest with a closed drainage system to keep the remaining lung expanded. The first lobectomy of this series happened in 1918. In 1939, Churchill and Belsey, from Bristol, England, described individual dissection and ligation of the elements of the hilum in pulmonary segmentectomy. As for pneumonectomy, a tourniquet, introduced by Shenstone and Janes from Toronto in 1932, was initially used. The entire hilum was tied with a thick cord, the lung was sectioned and then the stump of about $2 \mathrm{~cm}$ was subjected to a continuous suture. Such technique was used by Graham and Singer (1933) in the first (and successful) pneumonectomy for treating a lung carcinoma, which became another milestone in the history of thoracic surgery ${ }^{4}$.

The development of thoracic surgery in the first half of the twentieth century was directly linked to the treatment for pulmonary tuberculosis. The failure of the artificial pneumothorax in treating such pathology forced the appearance of the extrapleural thoracoplasty. Initially with the resection of of only a few ribs (second and third), then with more extensive thoracoplasties (from the second to up to the tenth) and with subperiosteal resection and many other variations of the technique. However, surgery was morbid and deforming. Therefore, new techniques for lung collapse were developed. The release of pleuropulmonary adhesions and filling of the pleural cavity with a variety of substances was described. The plombage was the variation of this technique which became the most famous, it consisted of extrapleural detachment and the filling of that space with various materials, among which the most popular were oil, polyethylene sheets and Lucite balls. Such technique had serious complications arising from the intolerance of the organism to the foreign bodies installed. The age of plombage ended with the appearance of the antituberculosis agents. After the advent of these agents, pulmonary resections of the affected areas became the most used surgical modalities ${ }^{5}$.

The Great World Wars also fostered significant developments for thoracic surgery. In the First World War, the principles for the treatment of open chest wounds and pleural empyema were established. In the Second World War, the focus was on the treatment of early decortication in the hemothorax.

A long time went by until Robert-Shaw, in England, 1972, developed the Double-lumen endotracheal tube. It allowed for the ventilation of only one lung, while the other, under atelectasis, was subjected to surgical intervention with greater ease. Such creation is particularly important in minimally invasive surgeries because it allows a better exposure of the pulmonary hilum structures. The development of endoscopy was also very important for the expansion of thoracic surgery. It enabled the use of tubes for the diagnosis and treatment of diseases of the larynx, trachea and bronchi.

\section{History of Thoracic Surgery in the University of São Paulo's Faculty of Medicine (FMUSP)}

In 1934, the infirmaries of the Clinical Medicine and Surgery Departments of the Faculty of Medicine were still installed in the Santa Casa de Misericórdia de São Paulo 
(São Paulo Holy House of Mercy). It was there, in its Male Surgery Ward, headed at that time by Professor Alípio Corrêa Netto, that two of his assistants, Dr. Euryclides de Jesus Zerbini and Dr. Eduardo Etzel, became the first surgeons to engage in the surgical treatment of thoracic and lung diseases, which until then was limited to the first attempts to treat pulmonary tuberculosis and pleural empyema, which gave rise to the creation, in that ward of the Santa Casa, of the Faculty's first Hospital Ward of Thoracic and Lung Surgery ${ }^{6}$.

Thus, Thorax Surgery and Lung Surgery began. Shortly after, it would witness the heyday of lung surgery, which was a relatively new medical activity at that point. Its success was due to the severity that tuberculosis, the predominant disease at that time, which was difficult to heal, posed to public health. Although they had already been discovered, antibiotics were still out of reach for the vast majority of the health professionals. Tuberculosis was fought then with rest, enhanced nutrition and some heroic surgeries.

Professor Zerbini was one of the surgeons concerned with the performance of lung surgeries. In 1939, the Infirmaries in the Clinical Medicine and Surgery Departments had already been transferred to the Clinical Hospital, when Professor Zerbini was nominated First Assistant of the First Surgical Clinic in the Surgery Department. Keeping his interest in lung surgery, Zerbini defended, in March 1941, his doctoral thesis, which analyzed the Surgical Treatment of Pulmonary Tuberculosis through the Extrapleural Pneumothorax. The success of this surgery would have repercussions which, in a way, would deeply change the way lung surgery came to be seen and to evolve in the following years.

Professor Zerbini was an excellent lung surgeon. In February of the following year, 1942, he performed his first emergency thoracotomy to remove a piece of iron that was stuck in the wall of the left ventricle, causing bleeding and hemopericardium in a child. The fragment was removed, the wound in the ventricle was sutured and a bleeding coronary branch was ligated, with the patient doing well. The success of the operation had great repercussion.

In one of his typical gestures, Euryclides Zerbini decided he should spend some time abroad and know how to thoracic surgery evolved in the major medical centers.
He would go to the United States and England. It was the year 1943, World War II was at its peak, which did not dissuaded, not even minimally, the doctor from moving forward. He has been to Saint Louis, Boston and to the Indiana Hospital. When he returned to Brazil, he brought the first endotracheal tubes.

In 1954, the Ward of Thoracic and Lung Surgery that had been created in the Santa Casa and established in the Clinical Hospital provided the didactic and scientific basis for the creation of a new discipline in the Surgery Department, called the Thoracic Surgery Discipline. Dr. Zerbini was nominated for its headship. It was, so to speak, the heyday of lung surgery, while cardiac surgery was still more of a possibility than an actual medical practice.

In 1956 and 1957, FMUSP's Department of Cardiopneumology was institutionalized in the Department of Clinical Medicine and in the Department of Surgery. Its creation came from the union of the Cardiology and Pneumology disciplines and the Thoracic Surgery Discipline which belonged respectively to these Departments and, at that time, were headed by professors Luiz Venere Décourt and Euryclides Jesus Zerbini. These disciplines had started with small medical services dedicated to the clinical and surgical treatment of the lung and heart diseases, which had been developing in the United States and Europe since the 1930s and 1940s, whose skills and knowledge Dr. Zerbini had brought to the Faculty.

But antibiotics became more accessible, and the terrible tuberculosis finally started to be controlled. And that time is another crucial fact occurred: with the advent of cardiopulmonary bypass, heart surgery began to develop. The heart was no longer an untouchable organ. It was a new world for surgeons. Operating a heart was an iconic achievement. And its possibilities seduced the one who was considered one of the most skilled thoracic surgeons, Dr. Euryclides de Jesus Zerbini himself. This new interest led him back to the United States, from where he returned in 1957 to perform the first heart surgeries "in the open", with the use of a cardiopulmonary bypass machine, at the Clinical Hospital. This machine arrived in Brazil in the hands of Dr. Nagib Curi who had been living in the United States for eight years specializing in thoracic surgery, when Professor Zerbini asked him to return to Brazil. By July 1964, a thousand surgeries of this kind had been performed. 
With the growth of heart surgery, Professor Alípio Corrêa Netto turned the Ward of Thoracic Surgery into the Ward of Cardiothoracic Surgery, headed by the Thoracic Surgery Discipline of the Department of Surgery, whose first head was Professor Zerbini. The scope of the Thoracic Surgery Discipline encompassed then the surgical treatment of thoracic, lung, heart and thoracic aorta diseases. The Ward of Lung Surgery, linked to this subject, headed by Professor Rubens Monteiro de Arruda, who was aided by Dr. Nagib Curi both in the conduct of service and in the teaching of the specialty, began providing care to patients with general thoracic disorders, in infirmary and ambulatory, throughout the CH's Complex.

A fundamental milestone in the history of thoracic and cardiovascular surgery at the FMUSP was the performance of the first Heart Transplant in Brazil in 1968 by Prof. Zerbini's team. The Heart Institute exists only due to this surgery, no doubt. The subject was on the news for a long time. Dr. Zerbini, Dr. Luiz Venere Décourt - Clinical Medicine Professor and creator of the Clinical Cardiology and Heart Surgery Disciplines, together with Dr. Zerbini - and part of his team were praised on newspapers, on the radio and on the TV. The population was delighted, and so were government authorities. The two professors knew how to take advantage of that fame, they saw in it the opportunity to make the dream of creating an institute dedicated to the development of Clinical and Surgical Cardiology come true. The president at that time, Artur da Costa e Silva, the governor of São Paulo, Abreu Sodré, and especially the then Finance Minister, Delfim Netto, who was part of the University of São Paulo, gave great support to the building of what would be the Heart Institute. The 3000-square-meters land on which the InCor would be built was transferred on December 5, 1966, by the São Paulo Secretary of Health, to the Clinical Hospital and later to the Emilio Ribas Hospital, whose area extended from Dr. Arnaldo Avenue to Dr. Enéas de Carvalho Aguiar Avenue. The director of the Emílio Ribas Hospital, professor Otávio Martins Toledo, was a friend of Dr. Zerbini's and ceded the area on which the first InCor block was to be built.

On January 21, 1969 the construction of the building intended to house the Incor, the Heart Institute of the Clinical Hospital of the University of São Paulo's Faculty of Medicine, began. But financial difficulties have caused its building to drag on. Five years passed from the beginning of the works in 1969 until the end of its building, in late 1974. The first patient was only attended on January 10, 1977, and the first heart surgery took place on October 24, 1978 (Figure 1). However, the Ward of Thoracic Surgery still kept the vast majority of its activities concentrated in the Central Institute of the HCFMUSP.

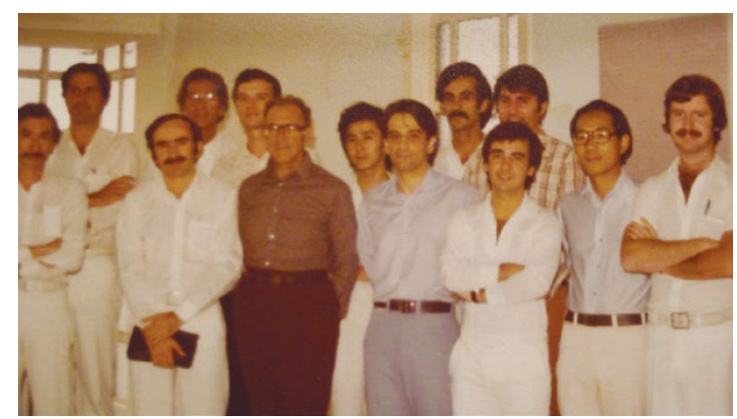

Figure 1. Prof. Zerbini (wearing dark clothes) poses among the group of interns, accompanied by his assistants, in 1977

Professor Zerbini retired in 1983, leaving vacant the position of Full Professor of the Thoracic Surgery Discipline, taken, after a public tender, by Professor Adib Domingos Jatene. One year later, with the death of Professor Rubens Monteiro de Arruda, the headness of the Ward of Thoracic Surgery started being performed by Dr. Nagib Curi. At that time, Thoracic Surgery was treading, even though slowly, but always progressively, relevant and prestigious paths that, in a way, it had lost decades before. Its importance was under recovery thanks to the new diagnostic methods driven by computed tomography, by the development of new surgical techniques and in the consolidation of the concept of "minimally invasive" surgeries in the 1980s. The demand for these surgeries began a process of growth that extends to the present day.

The appearance of the endoscopic and then videoendoscopic techniques made Thoracic Surgery broaden its performance field, but perhaps the most auspicious thing was seeing professionals regain interest for it. It was a process that was rising around the world and not only at the University of São Paulo's Faculty of Medicine. This would become even more evident and visible in the next decade, when a new generation of professionals began to assume leadership positions in the Specialty and in the Heart Institute. Drs. Fábio Jatene, Ricardo Beyruti, José 
Ribas, Ângelo Fernandes and Hélio Minamoto formed the third generation of thoracic surgery, so to speak, if we consider that doctors Alípio and Zerbini were in the first one and Adib Jatene, Nagib Curi, Euclydes Marques were in the second one.

On October 1st, 1985, a historic step was taken towards the configuration of the profile of the teaching that would be practiced on the premises of the Heart Institute. On that date, the advices of the Department of Clinical Medicine and the Department of Surgery and the Congregation of the Faculty of Medicine approved the junction of their respective disciplines of Cardiology, Pneumology and Thoracic Surgery so that the current Department of Cardiology was created. On September 3, 1986, the first Council of the Department of Cardiopneumology was elected.

Later that year the Council approved its Internal Regulations, in which it defined the Cardiology, Thoracic and Cardiovascular Surgery and Pneumology Disciplines as its three official disciplines. On December 16, 1993, a profound administrative change took place with the creation of surgical units by field of work. On this date, Professor Fábio Biscegli Jatene began exerting the function-activity of Technical Director of Health Service II, in the Lung Surgery Ward of HCFMUSP's Clinical Surgery Division. For the surgical units the following physicians were nominated as responsible surgeons: Pleural Diseases Unit, under Professor José Ribas Milanez de Campos's responsibility; Lung Neoplasms Unit, for which Dr. Ricardo Beyruti was responsible; Thoracic Wall Unit, Dr. Ângelo Fernandes; Mediastinum Unit, under the responsibility of Professor Paulo M. Pego Fernandes; Advanced Lung Diseases Unit and Lung Transplant, Professor Fábio Biscegli Jatene; Suppurative Diseases Unit, Dr. Luis Miguel Melero Sancho; General Thoracic Surgery and Diagnostic Methods Unit, under doctors Hélio Minamoto and Miguel Lia Tede's responsibility; and Trachea and Airways Unit, for which Dr. Luiz Tarcísio de Brito Filomeno is responsible (Figure 2).

The group's growth was also an important factor for the creation, to some extent, of an unexpected tightening of connections between Thoracic Surgery and Pneumology. Until then these services have operated completely in separate, especially when they were on different floors, with headships located a little further away. When both moved to the third floor of the ICHC the clinics began dialoguing a little more and their ambulatories began to grow a little closer.

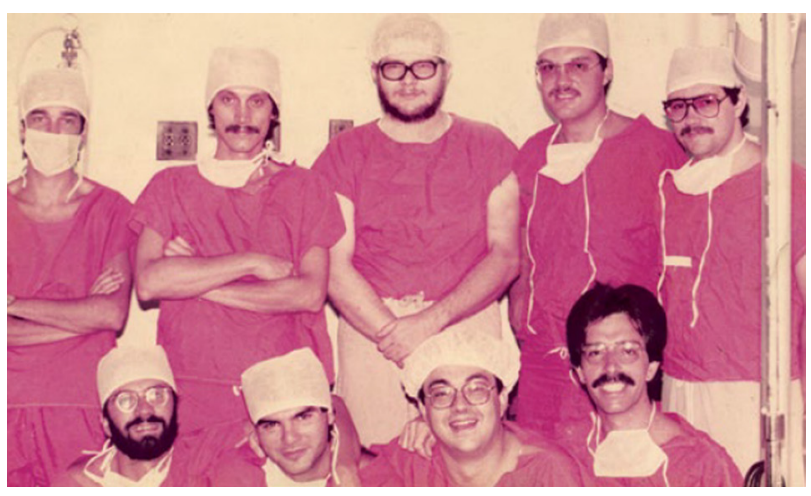

Figure 2. Thoracic Staff of Surgeons (third generation)

In December, 1990, the Thoracic Surgery's firs lung transplant was performed. But these surgeries were performed sporadically until 2003, when the restructuring of this program occurred and transplants started being performed at InCor. This restructuring process included the formation of a group of doctors, surgeons and a multidisciplinary team, all dedicated exclusively to the program. It is currently one of the most active groups in Brazil and the one with broader national experience in bilateral transplants, with over a hundred transplants performed. On March 2, 2012, InCor's Lung Transplant Group conducted another remarkable feat: the first transplant in Latin America using a reconditioned lung. The ex vivo lung reconditioning technique is being developed in recent years to make initially rejected lungs from donors viable in order to perform the transplant.

Since 2009, with the inauguration of the Octavio Frias de Oliveira Cancer Institute of the State of São Paulo (Instituto do Câncer do Estado de São Paulo Octavio Frias de Oliveira - ICESP), there has been a significant increase in the number of thoracic oncology procedures, nearly doubling the Discipline's capacity of assisting patients with intrathoracic neoplasms. And since we are talking about the three generations of professionals involved in the construction of the Thoracic's History, there in ICESP the fourth generation blossoms. In the Cancer Institute, doctors Ricardo Mingarini Terra, Pedro Henrique Xavier Nabuco de Araujo and Letícia Lauricella are involved in 
the organization of a broad, unprecedented and complex database, with the registration of clinical and surgical data from lung surgeries for lung cancer.

The national and international relevance of the $\mathrm{CH}$ FMUSP's Thoracic Surgery can once again be endorsed when the list of surgical procedures that were introduced, modified, improved or disseminated by the Ward are observed. A few examples are: the use of "Pigtail" catheter for pleural drainage, the employment of prosthetics in complex tracheal diseases, percutaneous tracheostomy, videothoracoscopy, sympathectomy by videothoracoscopy for the treatment of hyperhidrosis, thromboendarterectomy in patients with chronic pulmonary embolism, the videothoracoscopic treatment of chest wall deformities, bilateral lung transplants.

A significant increase in the Discipline's of scientific production would occur was a natural result of the improvement of the teams. There was a significant increase in published articles, in the defense and advisory of doctoral theses, as well as the participation of the Discipline's group of surgeons in the presentations of scientific studies in major national and international conferences. Such growth caused the service to take the lead in the national setting and undoubtedly contributed to the raising of funds for research from funding agencies, allowing, in a virtuous circle, the development of more sophisticated projects.

Due to this increase in activities, in 2006 the Thoracic Surgery Discipline of the Department of Cardiology was created, and Professor Fábio Biscegli Jatene, who was indicated by tender, was its first Full Professor. In 2013, Professor Paulo Manuel Pêgo-Fernandes assumed this very position, becoming the second full professor of our Discipline (Figure 3).

The Thoracic Surgery has two research laboratories: the InCor Surgical Anatomical Laboratory, in which the research projects of the group, both clinical and experimental, the activities of preparation and preservation of heart and lung anatomy pieces for study and research, a sector dedicated to medical illustration and filming and editing of technical and scientific videos are centralized and managed, and the Thoracic Surgery Research Laboratory, in which the projects for experiments in animals, especially those related to lung transplantation, are developed.

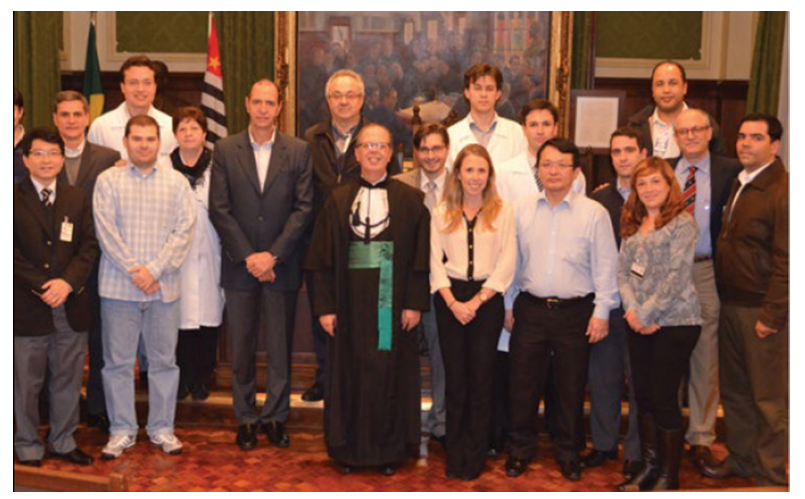

Figure 3. Prof. Paulo Pêgo Fernandes and the Thoracic Surgery Team shortly after the tender for Full Professor, in 2013

Throughout its history, Thoracic Surgery has trained many hundreds of qualified professionals coming from all corners of Brazil and of the world. The importance and density of its undergraduate and graduate education speak for themselves. When it comes from undergraduate education, since 1993, the Thoracic Surgery Ward has been co-responsible for the Thoracic and Cardiovascular Surgery Module taught to students in the 4th year of Medical School in the University of São Paulo's Faculty of Medicine. The goal is to modernize the teaching tools, supported by practical activities in the Medical Skills and Experimental Surgery Laboratory, in addition to theoretical classes and visits to the infirmaries. The purchase of some surgery simulators, which make learning more dynamic and interactive, was also requested. The Discipline edited, in 2010, the "Manual of Basic Thoracic Surgery", and, in 2011, the "Manual of Oncologic Thoracic Surgery". The goal was to face the challenge of reconciling the amount of information with the time that students have to absorb it (Figure 4).

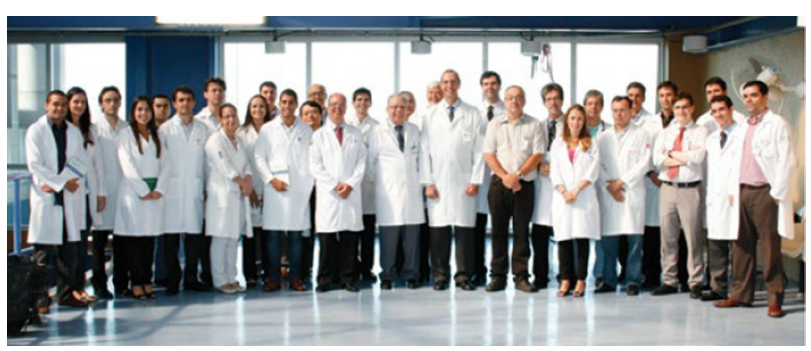

Figure 4. The Thoracic Surgery Team, with residents, assistants and visitors at the launch of the "Manual of Basic Thoracic Surgery" for the undergraduates, in 2011

Currently, the FMUSP Thoracic Surgery Discipline, in the Clinical Hospital's scope, is composed of a Director 
of Division, a Director of Service, a Medical Supervisor, 13 medical assistants who were divided between the InCor Clinical Complex and the ICESP. Regarding the University of São Paulo's Faculty of Medicine, the Discipline has a Titular Professor and Doctor-Professors, one Full Professor, in addition to Associate Professors. The thoracic surgery residency features 13 residents and foreign language intern, in addition to a preceptor physician and an oncological thoracic surgery fellow. Currently, the Discipline holds nearly 10000 ambulatory attendances and nearly 2000 operations annually, in addition an amount close to 800 of interconsultations of patients admitted to other clinics.

\section{Thoracic Surgery in the Twenty First Century}

As mentioned previously, the great "resumption" of Thoracic Surgery from the last three decades is due to the appearance of new diagnostic methods such as computed tomography, through the development of new surgical techniques and in the consolidation of the concept of "minimally invasive" surgeries It was then possible to diagnose and treat diseases in a less traumatic way and with progressively better results.

\section{REFERENCES}

1. Wilkins Jr EW, Urschel Jr HC. General thoracic surgery: history and development. In: Pearson FG, Cooper JD, Deslauriers J, Ginsberg RJ, Hiebert CA, Patterson GA, Urschel Jr HC. Thoracic surgery. 2nd ed. Philadelphia: Churchill Livingstone; 2002.

2. Jacobaeus HC. The cauterization os adhesions in artificial pneumotorax treatment of pulmonary tuberculosis under thoracoscopic control. Proc R Soc Med. 1923;16(Electro There Sect):45-62.

3. Eloesser L. Birth of modern chest surgery and von Mikulicz's part in it. J Thorac Cardiovasc Surg. 1965;50(5):757-8.
This evolution did not cease. Methods which are even less invasive are constantly evolving. In Thoracic Surgery we can highlight endoscopic interventions and videothoracoscopic and robotic surgery. The endoscopic methods of diagnosis will become more refined with the improvement of endobronchial ultrasound, allowing for a more accurate and safe acquisition of lung, mediastinum and thoracic lymph nodes tissue samples. Airway prostheses will become increasingly accessible and responsive to the physiology of the tracheobronchial tree. Pleural cavity interventions will be less traumatic and it will be possible to perform them on an outpatient basis and without the need for general anesthesia. Robotics is expected to be improved, the cost tends to decrease and new advances such as access through only one portal should further boost its use. The dissemination of integrated surgery rooms will enable more and more surgeries to be guided by imaging tests. Therefore, these surgeries will become more accurate and smaller in size. Thus, the growth observed in recent decades shall last for many decades more.

4. Eloesser L. Milestones in chest surgery. J Thorac Cardiovasc Surg. 1970;60(2):157-65.

5. Overholt RH, Langer L. Pulmonary resection in the treatment of tuberculosis: present-day technique and results. J Thorac Surg. 1946;15(6):384-417.

6. Pêgo-Fernandes PM, de Campos JRM. 80 anos de história da Disciplina de Cirurgia Torácica da FMUSP. São Paulo: FMUSP; 2014. Available at: http://www.cirurgiatoracica.org. br/wp-content/uploads/2015/03/miolo_livro_8_final_ok.pdf. 